\title{
Molybdenum-Catalyzed Sustainable Friedländer Synthesis of Quinolines
}

\author{
Rubén Rubio-Presa, ${ }^{\mathrm{a}}$ Samuel Suárez-Pantiga,${ }^{\mathrm{a}}$ María R. Pedrosa, ${ }^{\mathrm{a}}$ and \\ Roberto Sanz ${ }^{\mathrm{a}, *}$
}

a Departamento de Química, Facultad de Ciencias, Universidad de Burgos, Pza. Misael Bañuelos, s/n, 09001 Burgos, Spain E-mail: rsd@ubu.es

Received: February 26, 2018; Revised: March 22, 2018; Published online:

Supporting information for this article is available on the WWW under https://doi.org/10.1002/adsc.201800278

\begin{abstract}
Polysubstituted quinolines have been efficiently synthesized from nitroarenes and glycols, as reducing agents, under dioxomolybdenum(VI)catalysis. Interestingly, the waste reduction byproduct is incorporated into the final heterocycle. This method represents an efficient and sustainable variant of the Friedländer synthesis of quinolines.

Keywords: Friedländer reaction; microwave heating; molybdenum; nitroarenes; quinolines
\end{abstract}

The quinoline moiety is one of the most important heterocyclic scaffolds in medicinal chemistry due to its wide range of biological and pharmaceutical applications. ${ }^{[1]}$ Classical approaches for the preparation of quinolines possess important drawbacks such as the use of expensive starting materials or catalysts and the co-generation of large amount of wastes. ${ }^{[2]}$ However, more eco-friendly synthetic processes for accessing these heterocycles have been also reported. ${ }^{[3]}$ Among the known methods for quinoline synthesis, being the majority of them based on the condensation of aniline derivatives with glycerol or carbonyl compounds, the Friedländer reaction is one of the most used approaches. ${ }^{[4]}$ It consists in the acid-promoted condensation, and subsequent cyclodehydration, of an aromatic 2 -amino carbonyl compound with selected $\alpha$ methylene carbonyls. One of the main disadvantages of this reaction, as well as of the most of known methodologies, is the required use of $o$-aminobenzaldehydes, or related compounds, which are relatively unstable and should be previously prepared, typically by reduction of the corresponding aromatic $o$-nitrocarbonyls. In this context, some one-pot variants of the Friedländer synthesis have been described starting from easily available $o$-nitrobenzaldehydes, although most of them require large excess (4-5 equiv.) of reducing agents such as $\mathrm{SnCl}_{2}$ or $\mathrm{Fe}$ [Scheme 1,
Eq. (1)]. ${ }^{[5]}$ Another alternative of the Friedländer reaction involves the use of $\alpha$-2-aminoaryl alcohols, which mainly evolve through metal-catalyzed dehydrogenative $N$-heterocyclizations. ${ }^{[6]}$ As a significant improvement of these processes, it has been reported more recently the $\mathrm{Ru}$-catalyzed synthesis of quinolines from alcohols, as hydrogen donors, and 2-nitrobenzaldehydes or $\alpha$-2-nitroaryl alcohols [Scheme 1, Eq. (2)]. ${ }^{[7]}$

During the last years we have been interested in the development of oxygen atom transfer reactions

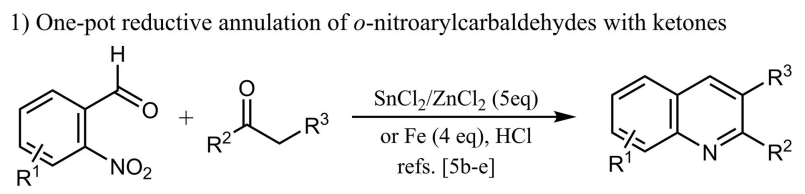

2) Ru-catalyzed hydrogen transfer-annulation with alcohols

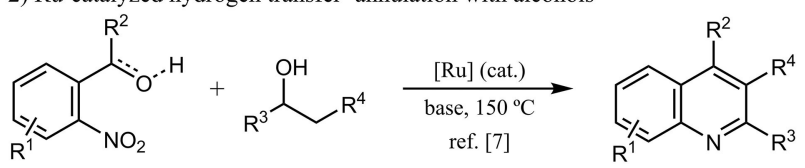

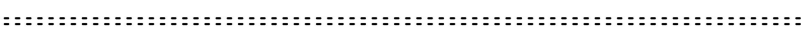

3) This work:

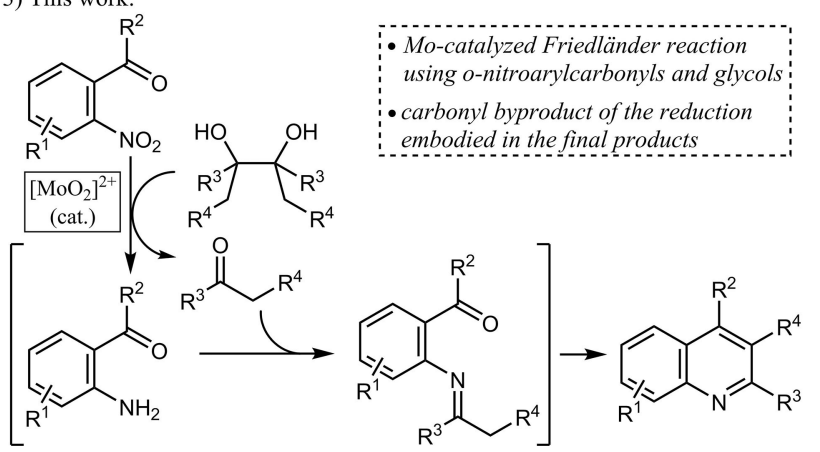

Scheme 1. Reported synthesis of quinolines from 2-nitrobenzaldehydes and our proposal under $\left[\mathrm{MoO}_{2}\right]^{2+}$ catalysis. 
catalyzed by nontoxic and readily available dioxomolybdenum(VI) complexes. ${ }^{[8]}$ Specifically, we have described that pinacol is able to act as an oxygen acceptor for the chemoselective reduction of nitroaromatics. ${ }^{[9]}$ Based on this process that only releases water and acetone as byproducts, we have more recently reported the synthesis of nitrogenated polyheterocycles from nitroarenes using 1,2-diols as reducing agents and with reuse of the waste reduction byproduct. $^{[10]}$ The strategy of using the byproduct generated in the first step of a given sequence as a reagent or catalyst for the following one, therefore benefiting the downstream reaction in a multistep synthesis, has been pioneered by Shibasaki ${ }^{[11]}$ and Zhou. ${ }^{[12]}$ However, although it is a highly interesting concept for the development of sustainable tandem reactions, not many examples have been reported in this underexplored field. ${ }^{[13]}$

In this context, and taking advantage of the high functional group tolerance of our nitro reduction with glycols that allows the presence of carbonyl groups, we envisaged a new one-pot Friedländer quinoline synthesis from $o$-nitroarylcarbaldehydes or ketones and glycols as reducing agents, whose carbonyl reduction byproduct would be incorporated in the final heterocycle as the $\mathrm{C}_{2}-\mathrm{C}_{3}$ fragment [Scheme 1, Eq. (3)]. We herein report a new demonstration of the concept of reusing a waste byproduct as a reactant for the next step applied to the sustainable and efficient preparation of a wide variety of regioselectively functionalized quinolines.

In an initial experiment using 5-chloro-2-nitrobenzaldehyde $\mathbf{1} \mathbf{a}$ and 2,3-diphenyl-2,3-butanediol $\mathbf{2 a}$ as model substrates, $\mathrm{MoO}_{2} \mathrm{Cl}_{2}(\mathrm{dmf})_{2}$ as catalyst in DMA as solvent and under microwave irradiation, ${ }^{[14]} \mathrm{a}$ mixture of the desired quinoline 3 aa and the corresponding aniline $4 \mathbf{a}$ was obtained at $130^{\circ} \mathrm{C}$ with no complete conversion (Table 1, entry 1). Gratifyingly, raising the temperature led to complete consumption of the starting material (entry 2), and at $180^{\circ} \mathrm{C}$ intermediate aniline $4 \mathbf{a}$ was also completely transformed into quinoline $\mathbf{3}$ aa (entry 3 ). As expected, no reaction took place in the absence of catalyst (entry 4) and, in addition, the process could also be carried out under conventional heating, although a higher load of the catalyst and longer reaction times were required (entry 5).

It should be noted that $\mathrm{MoO}_{2} \mathrm{Cl}_{2}(\mathrm{dmf})_{2}$ is a readily available catalyst, easily prepared from inexpensive $\mathrm{MoO}_{3}(50-70 € / \mathrm{mol})$ or $\mathrm{Na}_{2} \mathrm{MoO}_{4}(75-100 € / \mathrm{mol}),{ }^{[15]}$ that herein appears to serve the dual role of oxotransfer and Friedländer annulation catalyst. With the best conditions in our hands, we then studied the scope of this new reaction employing a variety of commercially or easily available $o$-nitrobenzaldehydes $\mathbf{1} \mathbf{a}-\mathbf{l}$, which were reacted with glycol $\mathbf{2 a}$ under the established conditions (Scheme 2). The benzenoid ring
Table 1. Optimization of reaction conditions for the synthesis of quinoline $\mathbf{3} \mathbf{a a} .^{[a]}$

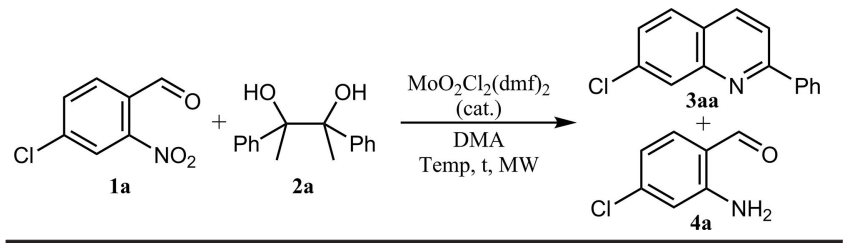

\begin{tabular}{lllllll}
\hline Entry & $\begin{array}{l}\text { Catalyst } \\
{[\mathrm{mol} \%]}\end{array}$ & $\begin{array}{l}\text { Temp. } \\
{\left[{ }^{\circ} \mathrm{C}\right]}\end{array}$ & $\begin{array}{l}\mathrm{t} \\
(\mathrm{min})\end{array}$ & $\begin{array}{l}\text { Conversion } \\
(\%)^{[\mathrm{b}]}\end{array}$ & $\begin{array}{l}\mathbf{3 a a} / \mathbf{4 a} \\
\text { ratio }^{[\mathrm{b}]}\end{array}$ & $\begin{array}{l}\text { Yield } \\
{[\%]^{[\mathrm{c}]}}\end{array}$ \\
\hline 1 & 5 & 130 & 20 & 75 & $1 / 6$ & - \\
2 & 5 & 150 & 20 & 100 & $1 / 3$ & - \\
3 & 5 & 180 & 20 & 100 & $1 / 0$ & 75 \\
4 & - & 180 & 20 & 0 & - & - \\
$5^{[\mathrm{d}]}$ & 10 & 180 & 120 & 100 & $1 / 0$ & 61 \\
\hline
\end{tabular}

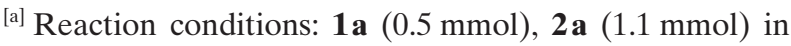
DMA $(1 \mathrm{~mL})$ under MW irradiation unless otherwise stated.

${ }^{[b]}$ Determined by ${ }^{1} \mathrm{H}$ NMR analysis.

${ }^{[c]}$ Isolated yield of $\mathbf{3}$ aa.

${ }^{\text {[d] }}$ Carried out under conventional heating in a screw-cap sealed tube.

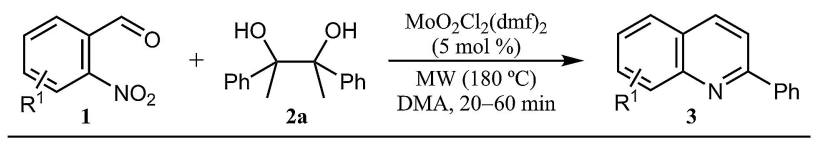<smiles>Clc1ccc2nc(-c3ccccc3)ccc2c1</smiles><smiles>Clc1cccc2nc(-c3ccccc3)ccc12</smiles>
3aa $(75 \%)(61 \%)^{[a]}$ 3ba $(73 \%)$<smiles>Clc1ccc2ccc(-c3ccccc3)nc2c1</smiles>
3ca $(80 \%)$<smiles>Clc1cccc2ccc(-c3ccccc3)nc12</smiles><smiles>Brc1ccc2ccc(-c3ccccc3)nc2c1</smiles><smiles>FC(F)(F)c1ccc2ccc(-c3ccccc3)nc2c1</smiles><smiles>COC(=O)c1ccc2nc(-c3ccccc3)ccc2c1</smiles><smiles>CN(C)c1ccc2ccc(-c3ccccc3)nc2c1</smiles><smiles>COc1cccc2ccc(-c3ccccc3)nc12</smiles><smiles>COc1cc2ccc(-c3ccccc3)nc2cc1OC</smiles><smiles></smiles>

${ }^{[a]}$ Conventional heating. ${ }^{[b]}$ PTSA (1 eq) was added.

Scheme 2. Mo-catalyzed synthesis of 2-phenylquinolines $\mathbf{3}$ from $o$-nitrobenzaldehydes 1 and 2,3-diphenylbutane-2,3-diol (2a).

of 2-phenylquinolines $\mathbf{3}$ can be functionalized with halogens as substituents $(\mathrm{Cl}, \mathrm{Br})$ at any of the possible positions, as shown with compounds 3 aa-3 ea that were obtained in high yields and offer convenient platforms for further derivatization. Other electronwithdrawing groups, such as trifluoromethyl and 
methoxycarbonyl, are also tolerated on the starting nitroaromatic delivering the corresponding quinolines 3 fa and 3 ga also in high yields. For obtaining estercontaining quinoline $\mathbf{3}$ ga, $p$-toluenesulfonic acid (PTSA) was added in order to promote the cyclization. ${ }^{[16]}$ Simple 2-phenylquinoline 3 ha could also be synthesized, as well as quinolines $\mathbf{3}$ ia-la bearing electron-donating groups such as methoxyl or dimethylamino, at different positions of the benzenoid ring. So, a wide variety of functional groups are tolerated in the starting nitroarene $\mathbf{1}$, thus leading to functionalized quinolines $\mathbf{3}$ aa-la.

The same reaction conditions were next applied to different di-tertiary glycols $\mathbf{2 b}-\mathbf{g},{ }^{[17]}$ which were treated with model $o$-nitrobenzaldehyde 1 a to establish the scope of the process regarding the nature of the reducing agent and, so, the substituents that could be located at positions $\mathrm{C} 2$ and $\mathrm{C} 3$ of the quinoline skeleton (Scheme 3). With glycols $\mathbf{2} \mathbf{b}, \mathbf{f}-\mathbf{h}$, bearing methyl groups $\left(\mathrm{R}^{4}=\mathrm{H}\right)$, it could be established that alkyl, as well as functionalized aryl or heteroaryl group, can be present as $\mathrm{R}^{3}$ substituent of the glycol thus leading to the corresponding 5-chloro-2-substituted quinolines $\mathbf{3}$ with (functionalized)aryl, hetero-

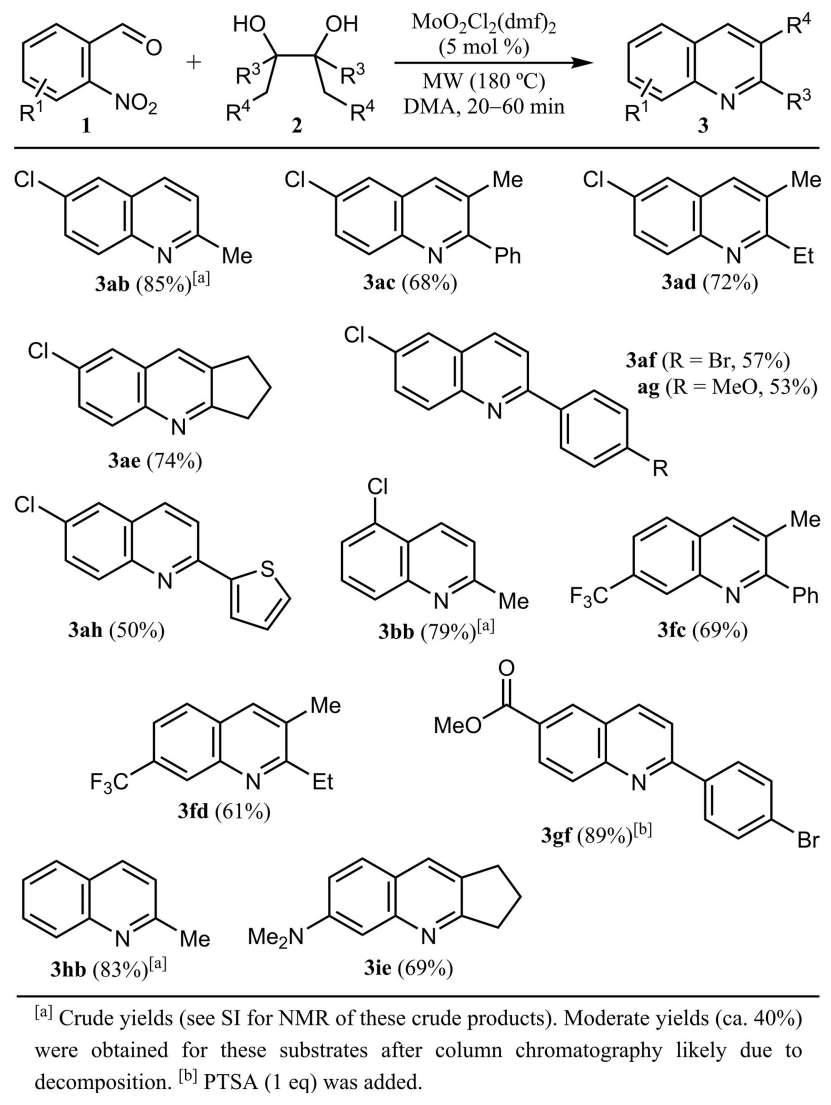

Scheme 3. Mo-catalyzed synthesis of regioselectively functionalized quinolines $\mathbf{3}$ from $o$-nitrobenzaldehydes $\mathbf{1}$ and different glycols 2 . aryl or alkyl groups at $\mathrm{C} 2$ in moderate to high yields. In addition, the $\mathrm{R}^{4}$ group of the glycol $\mathbf{2}$ could also be different from hydrogen allowing access to quinolines 3ac-ae further substituted at C3. Some of these new glycols 2 were also reacted with selected functionalized $o$-nitrobenzaldehydes $\mathbf{1}$ allowing the preparation of the corresponding quinolines $\mathbf{3}$, mostly in good yields. Again the synthesis of 5-methoxycarbonylsubstituted quinoline $\mathbf{3}$ gf required the addition of a stoichiometric amount of PTSA.

Finally, we decided to test our methodology with more challenging 2-nitroaryl ketones (Scheme 4). Submission of 2-nitroacetophenone $\mathbf{1} \mathbf{m}$ to the established reaction conditions, using pinacol $\mathbf{2 b}$ as glycol partner, resulted in 2-aminoacetophenone $\mathbf{4 m}$ as the major compound with only minor amounts of 2,4dimethylquinoline $\mathbf{3} \mathbf{m b}$. As the Mo-catalyzed reduction reaction of nitroaromatics using glycols as oxygen acceptors proved to be compatible with a wide variety of functional groups, we hypothesized that the presence of a metal co-catalyst would be well tolerated under these reductive conditions thus favouring the synthesis of the desired quinolines. After some experimentation, ${ }^{[18]}$ we identified $\mathrm{Sc}(\mathrm{OTf})_{3}$ as the most efficient Lewis acid co-catalyst for further promoting the desired quinoline formation although no complete conversion of aniline $\mathbf{4} \mathbf{m}$ could be achieved. So, the treatment of $\mathbf{1} \mathbf{m}$ with selected glycols $\mathbf{2}$ gave rise to 4methylquinolines $\mathbf{3} \mathbf{m a}-\mathbf{m e}$ in moderate yields, along with variable amounts of aniline $\mathbf{4 m}$. Interestingly, 4trifluoromethylated quinolines 3 na-ne could also be synthesized in moderate to good yields starting from easily available 2-nitrophenyl-trifluoroacetophenone 1n. ${ }^{[19]}$ It is worthy to note that the introduction of the trifluoromethyl group in heteroatomatics is of high interest in medicinal, agricultural, and material

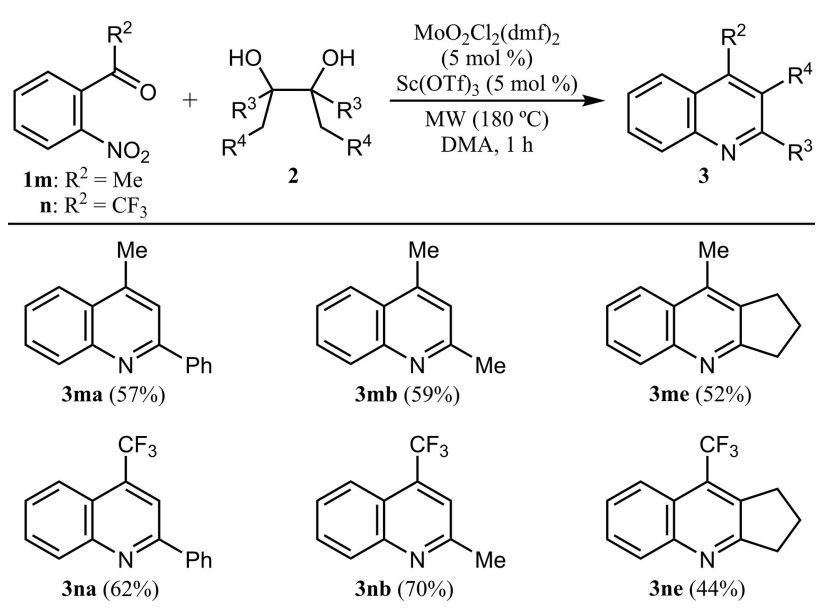

Scheme 4. 2,4-Disubstituted and 2,3,4-trisubstituted quinolines $\mathbf{3}$ from $o$-nitrophenyl ketones $\mathbf{1} \mathbf{m}, \mathbf{n}$ and selected glycols $2 \mathbf{a}, \mathbf{b}, \mathbf{e}$. 
chemistry because the presence of fluorine atoms can dramatically affect their properties. ${ }^{[20]}$

In summary, we have demonstrated that the concept of reusing the waste byproduct of a reaction as a reactant for the next step, embodied it into the final product, could be applied to a new catalytic version of the venerable Friedländer synthesis of quinolines. Readily available nitroarenes are used as the nitrogen source, and glycols as reducing agents and carbonyl source. Under dioxomolybenum(VI)catalysis, the nitro reduction, imine generation, and final condensation take place in a new domino process that involves the incorporation of the carbonyl reduction byproduct into the quinoline skeleton. This strategy shows broad substrate scope, tolerating both electron-withdrawing and electron-donating functionalities on the starting aromatic nitro carbonyl and a variety of di-tertiary glycols. For the synthesis of 4substituted quinolines this methodology is realized by relay actions of molybdenum and a Lewis acid. In addition, all products were obtained in good to high yields in short reaction times taking advantage from the microwave irradiation technique.

\section{Experimental Section}

\section{General Procedure for the Synthesis of Quinolines 3 from $o$-Nitrobenzaldehydes 1 and Glycols 2 Catalyzed by $\mathrm{MoO}_{2} \mathrm{Cl}_{2}(\mathrm{dmf})_{2}$}

In a $10 \mathrm{~mL}$ reaction vessel, the corresponding 2-nitrobenzaldehyde $\mathbf{1}(0.5 \mathrm{mmol})$ and 1,2-diol $2(1.1 \mathrm{mmol})$ were added to anhydrous DMA $(1 \mathrm{~mL})$. Then, $\mathrm{MoO}_{2} \mathrm{Cl}_{2}(\mathrm{dmf})_{2} \quad(9 \mathrm{mg}$, $0.025 \mathrm{mmol}, 5 \mathrm{~mol} \%$ ) was added and the vessel was sealed with a septum. The reaction mixture was stirred at $180^{\circ} \mathrm{C}$ for 20-60 min under microwave heating (maximum wattage: $150 \mathrm{~W}$ ). Alternatively, in a screw-cap sealed tube, the mixture of reagents (but using $10 \mathrm{~mol} \%$ of $\mathrm{MoO}_{2} \mathrm{Cl}_{2}(\mathrm{dmf})_{2}$ ) was stirred at $180^{\circ} \mathrm{C}$ for $2 \mathrm{~h}$ (oil bath temperature). After completion of the reaction, monitored by GC-MS, the mixture was cooled to rt, diluted with $\mathrm{Et}_{2} \mathrm{O}(30 \mathrm{~mL})$, and washed with a $1 / 1$ mixture of $0.3 \mathrm{M}$ aq. $\mathrm{NaOH} /$ brine $(3 \times$ $10 \mathrm{~mL}$ ). The organic layer was dried over anhydrous $\mathrm{Na}_{2} \mathrm{SO}_{4}$ and concentrated under reduced pressure. The residue was purified by deactivated silica gel flash column chromatography (hexane/EtOAc) to afford the corresponding quinoline 3. When methyl 3-formyl-4-nitrobenzoate (19) was employed as starting material, the addition of $p$-toluenesulfonic acid monohydrate (PTSA) (95 mg, $0.5 \mathrm{mmol}$ ) was also required to obtain the corresponding quinoline $\mathbf{3}$ ga or $\mathbf{3}$ gf. Characterization data and NMR spectra are presented in the Supporting Information.

\section{Acknowledgements}

Financial support from Junta de Castilla y León and FEDER (BU076U16) and Ministerio de Economía y Competitividad (MINECO) and FEDER (CTQ2016-75023-C2-1-P) is grate- fully acknowledged. R. R.-P. thanks Universidad de Burgos for a predoctoral contract. S. S.-P. thanks Junta de Castilla $y$ León and FEDER for a postdoctoral contract.

\section{References}

[1] a) J. P. Michael, Nat. Prod. Rep. 2008, 25, 166-187; b) K. Kaur, M. Jain, R. P. Reddy, R. Jain, Eur. J. Med. Chem. 2010, 45, 3245-3264; c) S. Vandekerckhove, M. D'hooghe, Bioorg. Med. Chem. 2015, 23, 5098-5119.

[2] For selected reviews, see: a) S. A. Yamashkin, E. A. Oreshkina, Chem. Heterocycl. Chem. 2006, 42, 701-718; b) S. Madapa, A. Tusi, S. Batra, Curr. Org. Chem. 2008, 12, 1116-11; c) R. I. Khusnutdinov, A. R. Bayguzina, U. M. Dzhemilev, J. Organomet. Chem. 2014, 768, 75114; d) G. A. Ramann, B. J. Cowen, Molecules 2016, 21, 986-1008.

[3] For reviews related with greener approaches, see: a) S. M. Prajapati, K. D. Patel, R. H. Vekariya, S. N. Panchal, H. D. Patel, RSC Adv. 2014, 4, 24463-24476; b) V. F. Batista, D. C. G. A. Pinto, A. M. S. Silva, ACS Sustainable Chem. Eng. 2016, 4, 4064-4078; c) S. Naidoo, V. Jeena, Synthesis 2017, 49, 2621-2631.

[4] a) J. Marco-Contelles, E. Pérez-Mayoral, A. Samadi, M. C. Carreiras, E. Soriano, Chem. Rev. 2009, 109, 2652-2671; b) M. Fallah-Mehrjardi, Mini-Rev. Org. Chem. 2017, 14, 187-196.

[5] a) H. Eckert, Angew. Chem. 1981, 93, 216-218; Angew. Chem. Int. Ed. 1981, 20, 208-210; b) R. R. McNaughton, B. L. Miller, Org. Lett. 2003, 5, 4257-4259; c) M. K. Chaudhuri, S. Hussain, J. Chem. Sci. 2006, 118, 199-202; d) A.-H. Li, E. Ahmed, X. Chen, M. Cox, A. P. Crew, H.-Q. Dong, M. Jin, L. Ma, B. Panicker, K. W. Siu, A. G. Steinig, K. M. Stolz, P. A. R. Tavares, B. Volk, Q. Weng, D. Werner, M. J. Mulvihill, Org. Biomol. Chem. 2007, 5, 61-64; e) H. Venkatesan, F. M. Hocutt, T. K. Jones, M. H. Rabinowitz, J. Org. Chem. 2010, 75, 34883491; f) N. Sudhapriya, A. Nandakumar, P. T. Perumal, $R S C A d v$. 2014, 4, 58476-58480. For other recent syntheses of quinolines starting from nitroaromatics see, for instance: g) P. Kamath, R. C. Viner, S. C. Smith, M. Lal, Synlett 2017, 28, 1341-1345; h) V. A. Mamedov, V. L. Mamedova, V. V. Syakaev, D. E. Korshin, G. Z. Khikmatova, E. V. Mironova, O. B. Bazanova, I. K. Rizvanov, S. K. Latypov, Tetrahedron 2017, 73, 50825090.

[6] a) C. S. Cho, B. T. Kim, T.-J. Kim, S. C. Shim, Chem. Commun. 2001, 2576-2577. For recent examples, see: b) S. Das, D. Maiti, S. D. Sarkar, J. Org. Chem. 2018, 83, 2309-2316; c) D. W. Tan, H.-X. Li, D.-L. Zhu, H.-Y. Li, D. J. Young, J.-L. Yao, J.-P. Lang, Org. Lett. 2018, 20, 608-611; d) S. Parua, R. Sikari, S. Sinha, S. Das, G. Chakraborty, N. D. Paul, Org. Biomol. Chem. 2018, 16, 274-284. For a recent review, see: e) G. Chelucci, A. Porcheddu, Chem. Rec. 2017, 17, 200-216.

[7] a) F. Xie, M. Zhang, M. Chen, W. Lv, H. Jiang, ChemCatChem 2015, 7, 349-353; b) H.-J. Li, C.-C. Wang, S. Zhu, C.-Y. Dai, Y.-C. Wu, Adv. Synth. Catal. 2015, 357, 583-588. 
[8] a) R. Sanz, J. Escribano, R. Aguado, M. R. Pedrosa, F. J. Arnáiz, Adv. Synth. Catal. 2007, 349, 713-718; b) N. García, P. García-García, M. A. Fernández-Rodríguez, D. García, M. R. Pedrosa, F. J. Arnáiz, R. Sanz, Green Chem. 2013, 15, 999-1005; c) N. García, R. Rubio-Presa, P. García-García, M. A. Fernández-Rodríguez, M. R. Pedrosa, F. J. Arnáiz, R. Sanz, Green Chem. 2016, 18, 2335-2340. For a review, see: d) R. Sanz, M. R. Pedrosa, Curr. Org. Synth. 2009, 6, 239-263.

[9] a) N. García, P. García-García, M. A. Fernández-Rodríguez, R. Rubio, M. R. Pedrosa, F. J. Arnáiz, R. Sanz, Adv. Synth. Catal. 2012, 354, 321-327. For related deoxgygenation of $\mathrm{N}$-oxides and $\mathrm{N}$-hydroxybenzotriazoles, see: b) R. Rubio-Presa, M. A. Fernández-Rodríguez, M. R. Pedrosa, F. J. Arnáiz, R. Sanz, Adv. Synth. Catal. 2017, 359, 1752-1757. For a DFT study of the Mo-catalyzed pinacol cleavage, see: c) D. Lupp, N. J. Christensen, J. R. Dethlefsen, P. Fristrup, Chem. Eur. J. 2015, 21, 3435-3442.

[10] R. Rubio-Presa, M. R. Pedrosa, M. A. FernándezRodríguez, F. J. Arnáiz, R. Sanz, Org. Lett. 2017, 19, 5470-5473.

[11] T. Kinoshita, S. Okada, S.-R. Park, S. Matsunaga, M. Shibasaki, Angew. Chem. 2003, 115, 4828-4832; Angew. Chem. Int. Ed. 2003, 42, 4680-4684.

[12] J.-J. Cao, F. Zhou, J. Zhou, Angew. Chem. 2010, 122, 5096-5100; Angew. Chem. Int. Ed. 2010, 49, 4976-4980.

[13] Selected recent examples: a) J. Lu, P. H. Toy, Chem. Asian J. 2011, 6, 2251-2254; b) L. Chen, T.-D. Shi, J. Zhou, Chem. Asian J. 2013, 8, 556-559; c) F. Zhu, P.-W. $\mathrm{Xu}$, F. Zhou, C.-H. Wang, J. Zhou, Org. Lett. 2015, 17, 972-975; d) L. Chen, Y. Du, X.-P. Zeng, T.-D. Shi, F. Zhou, J. Zhou, Org. Lett. 2015, 17, 1557-1560; e) Q. Gao, S. Liu, X. Wu, J. Zhang, A Wu, J. Org. Chem.
2015, 80, 5984-5991; f) X.-P. Zeng, Z.-Y. Cao, X. Wang, L. Chen, F. Zhou, F. Zhu, C.-H. Wang, J. Zhou, J. Am. Chem. Soc. 2016, 138, 416-425; g) V. Pace, L. Castoldi, E. Mazzeo, M. Rui, T. Langer, W. Holzer, Angew. Chem. 2017, 129, 12851-12856; Angew. Chem. Int. Ed. 2017, 56, 12677-12682. For a review, see: h) J. Zhou, X.P. Zeng, in Multicatalyst System in Asymmetric Catalysis, (Ed.: J. Zhou), John Wiley \& Sons, New York, 2014, pp. 633-670.

[14] Microwave heating is nowadays well-recognized as a useful tool for sustainable chemistry. See: Microwave Heating as a Tool for Sustainable Chemistry, (Ed: N. E. Leadbeater), CRC Press, Boca Raton, FL, 2010.

[15] a) F. J. Arnáiz, Inorg. Synth. 1997, 31, 246-247; b) R. Sanz, J. Escribano, R. Aguado, M. R. Pedrosa, F. J. Arnáiz, Synthesis 2004, 1629-1632.

[16] In the absence of PTSA the intermediate methyl 4aminobenzoate $\mathbf{4 g}$ was obtained as major product along with the expected quinoline $\mathbf{3}$ ga.

[17] Symmetrical di-tertiary glycols $\mathbf{2}$ a,b,e are commercially available. The rest of diols $\mathbf{2}$ were prepared via pinacol coupling of ketones. See: T. Mukaiyama, T. Sato, J. Hanna, Chem. Lett. 1973, 1041-1044.

[18] See Supporting Information for further details.

[19] Obtained from the reaction of 2-nitrophenylmagnesium iodide with trifluoracetic anhydride. See: D. K. O'Dell, K. M. Nicholas, Heterocycles 2004, 63, 373-37.

[20] See, for instance: a) B. Jiang, Y.-G. Si, J. Org. Chem. 2002, 67, 9449-9451; b) J.-J. Dai, C. Fang, B. Xiao, J. Yi, J. Xu, Z.-J. Liu, X. Lu, L. Liu, Y. Fu, J. Am. Chem. Soc. 2013, 135, 8436-8439; c) Y. Ji, T. Brueckl, R. D. Baxter, Y. Fujiwara, I. B. Seiple, S. Su, D. G. Blackmond, P. S. Baran, Proc. Natl. Acad. Sci. USA 2011, 108, 1441114415. 


\section{UPDATES}

Molybdenum-Catalyzed Sustainable Friedländer

Synthesis of Quinolines

Adv. Synth. Catal. 2018, 360, 1-6

R. Rubio-Presa, S. Suárez-Pantiga, M. R. Pedrosa, R. Sanz*<smiles>[R]C(=O)c1ccc[R]#c1[N+](=O)[O-]</smiles>

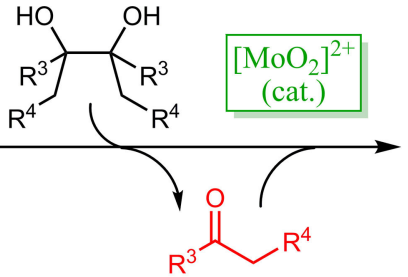<smiles>[R3]c1nc([R17])c2c(c1[R])CCC2</smiles>

31 examples up to $89 \%$ yield

Mo-catalyzed Friedländer reaction from nitroaromatics and glycols, with reduction byproduct embodied in the final quinoline: 